\title{
Accessory muscles of the anterior thoracic wall and axilla. Cadaveric, surgical and radiological incidence and clinical significance during breast and axillary surgery
}

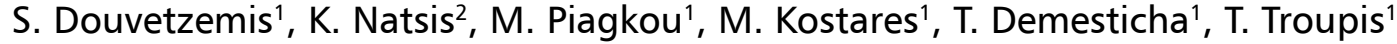 \\ ${ }^{1}$ Department of Anatomy, School of Medicine, Faculty of Health Sciences, National and Kapodistrian \\ University of Athens, Greece \\ ${ }^{2}$ Department of Anatomy and Surgical Anatomy, School of Medicine, Faculty of Health Sciences, \\ Aristotle University of Thessaloniki, Greece
}

[Received: 9 December 2018; Accepted: 23 December 2018]

Background: The present study aims to summarise the accessory muscles of the anterior thoracic wall and axilla that can be encountered during breast and axillary surgery and record their incidence and clinical significance. Moreover, the laterality of the atypical muscles is highlighted and possible gender dimorphism is referred. Accessory anterior thoracic wall muscles include: Langer's axillary arch, sternalis muscle, chondrocoracoideus, chondroepitrochlearis, chondrofascialis, pectoralis minimus, pectoralis quartus and pectoralis intermedius.

Materials and methods: The anatomical, surgical and radiological literature has been reviewed and an anatomical study on 48 Greek adult cadavers was performed.

Results: Literature review revealed the existence of accessory muscles of the anterior thoracic wall and axilla that have a significant incidence that can be considered high and may, therefore, have clinical significance. For the most common of these muscles, which are axillary arch (Langer's) and sternalis muscle, the cadaveric incidence is $10.30 \%$ and $7.67 \%$, respectively. In the current cadaveric study, accessory thoracic wall muscles were identified in two cadavers; namely a bilateral sternalis muscle (incidence 2.08\%) extending both to the anterior and posterior surface of the sternum and a left-sided chondrocoracoideus muscle (of Wood) (incidence 2.08\%).

Conclusions: Despite the fact that accessory anterior thoracic wall and axillary muscles are considered to be rare, it is evident that the incidence of at least some of them is high enough to encounter them in clinical practice. Thus, clinicians' awareness of these anatomical structures is advisable. (Folia Morphol 2019; 78, 3: 606-616)

Key words: accessory muscle, sternalis, axillary arch, chondrocoracoideus, chondroepitrochlearis, chondrofascialis, pectoralis minimus, pectoralis quartus, pectoralis intermedius, variation 


\section{INTRODUCTION}

Anatomical variations of the accessory thoracic wall muscles are well described; however, literature lacks systematic presentation of their incidence. Accessory muscles of the anterior thoracic wall include: Langer's axillary arch or axillary arch (LAA), sternalis muscle (S), chondrocoracoideus muscle (CC), chondroepitrochlearis muscle (CE), chondrofascialis muscle (CF), pectoralis minimus muscle (Pm), pectoralis quartus muscle $(\mathrm{Pq})$, and pectoralis intermedius muscle (Pi).

The LAA or axillopectoral or dorsoepitrochlearis or pectorodorsalis muscle or Achselbogen of Langer extends from the anterior border of the latissimus dorsi muscle (LD) to the tendon of pectoralis major (PM) crossing the axilla and is relatively frequent among the accessory thoracic wall muscles having an incidence of $5.3 \%[77,79]$.

Sternalis muscle $(\mathrm{S})$ or episternalis or parasternalis or presternalis or rectus sterni or rectus thoracis or rectus thoracicus superficialis or superficialis rectus abdominis overlies PM and is presented as a parasternal mass posteriorly to the superficial fascia of the anterior thoracic wall and anteriorly to the deep fascia [83]. There is variability in reported origins including the sternum, the inferior border of the clavicle, the sternocleidomastoid fascia, PM, and the upper ribs and their costal cartilages; while the insertion includes the lower ribs and their costal cartilages, PM, rectus abdominis sheath, and the external abdominal oblique muscle (EOM) aponeurosis [83, 88]. S prevalence is approximately $7.8 \%$ [74] with an intrapopulation variety ranging from $1 \%$ in Taiwanese to $23.5 \%$ in Northern Chinese [37].

The $\mathrm{Pi}$ or pectoralis tertius or xiphihumeralis is located in the deep layer of PM, below pectoralis minor (pm). It arises from the $3^{\text {rd }}$ to $5^{\text {th }}$ rib and runs almost parallel with pm [71]. It then attaches to the tendon of the short head of biceps brachii (BB) or to the coracoid process (CP). In case of coexistence with $\mathrm{Pq}$, the muscle is located between pm and $\mathrm{Pq}[4,24]$.

The $\mathrm{Pq}$ is a segmented part of PM [13]. It originates from the lower ribs, the lateral border of PM or the rectus sheath, and inserts into the bicipital groove or the upper arm fascia $[13,89]$. There has been a controversy in the reported prevalence of Pq which according to Natsis et al. [57] occurs with a low incidence of $2.8 \%$, although Bonastre et al. [14] found rates as high as $11 \%$ to $16 \%$.

The CE or thoracoepicondylaris or chondrohumeralis or chondrobrachialis or costohumeralis muscle originates from the lower ribs, the PM inferolateral aspect, or the EOM aponeurosis, which crosses the axilla and inserts in the medial intermuscular septum or the medial humeral epicondyle $[48,50]$. It is not uncommon to coexist with LAA [50].

The CF has been suggested to be an intermediate form between $\mathrm{Pq}$ and $\mathrm{CE}$, based on its insertion into the arm fascia. However, unlike $\mathrm{Pq}$, it lacks attachment to the PM and unlike CE it is not attached to the humerus [5].

The Pm or sternocostocoracoidian or sternochondrocoracoideus or chondrocoracoideus ventralis or sternochondrocoracoideus ventralis attaches medially to the $1^{\text {st }}[27,80]$ or $2^{\text {nd }}$ rib [80] and inserts onto the CP [27].

The CC or muscle of Wood is an extremely rare accessory thoracic wall muscle arising via slips from the $6^{\text {th }}$ to $8^{\text {th }}$ rib or the rectus sheath. It inserts into the $\mathrm{CP}$ and lies superficial to the coracobrachialis muscle $(\mathrm{CB})$, medial to the short head of $\mathrm{BB}$ and external to pm $[9,86]$.

The current study aims to record the incidence of the accessory muscles of the anterior thoracic wall and axilla based on a cadaveric study in a Greek adult population and on a detailed literature review. Moreover, the laterality and possible gender dimorphism of the atypical muscles are highlighted.

\section{MATERIALS AND METHODS}

The cadaveric study was performed in the Department of Anatomy, School of Medicine, National and Kapodistrian University of Athens between the last 12 years (2006-2018). Forty-eight (32 male and 16 female) formalin embalmed adult cadavers of Greek Caucasian origin, were dissected for tutorial purposes. They were donated to our Department after written informed consent for teaching purposes and they showed no evidence of previous trauma, skeletal disorder and breast or axilla surgery. They were dissected and examined for the presence of any accessory anterior thoracic wall or axillary muscles.

A meticulous literature review was performed on the electronic databases Pubmed and Google Scholar by using the keywords: "axillary arch" or "axillary arch of Langer" or "Langer's arch" or "dorsoepitrochlearis" or "axillopectoral muscle" or "pectorodorsalis muscle", "sternalis muscle" or "rectus sternalis" or "episternalis" or "parasternalis" or "presternalis" or "rectus sterni" or "rectus thoracis" or "rectus thoracicus superficialis" or "superficialis rectus abdominis", 

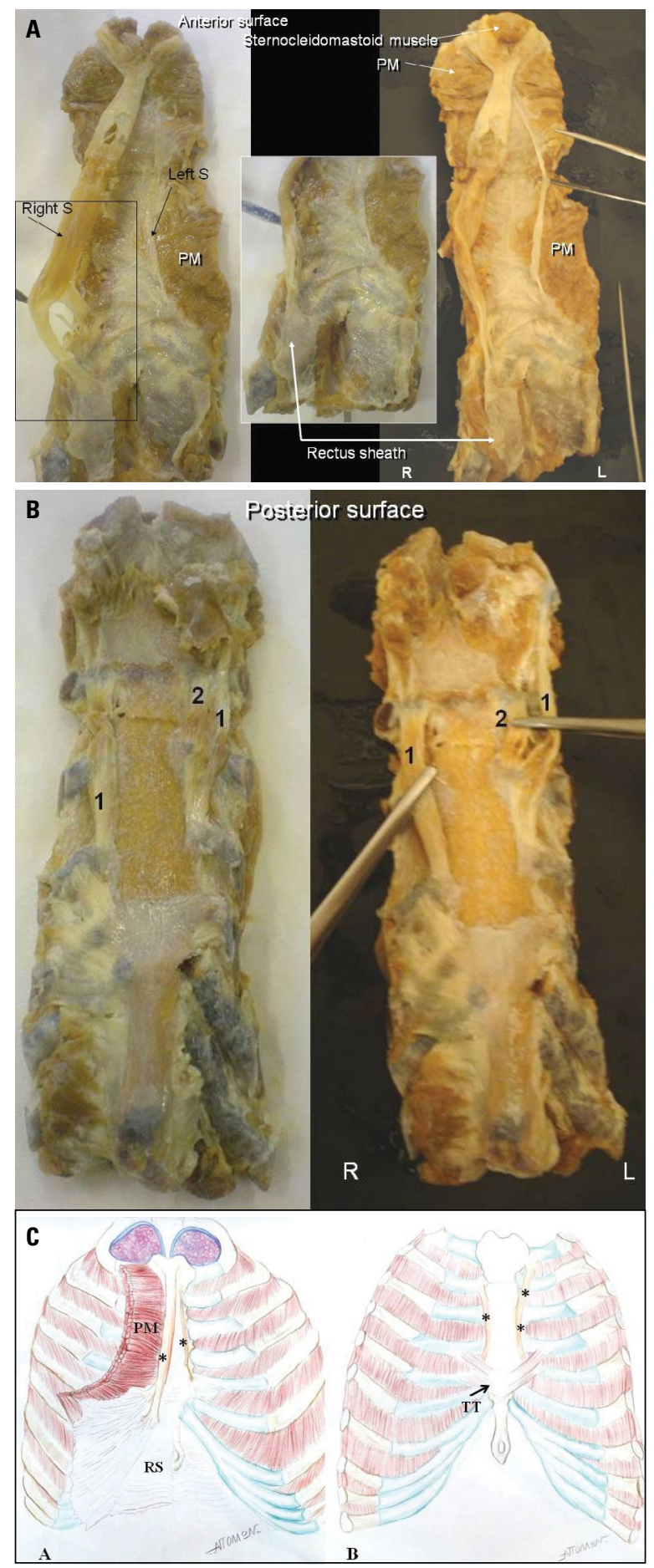

Figure 1. A. Anterior view of the atypical sternalis muscle $(\mathrm{S})$ situated both in right and left side ( $R$ and $L)$; $B$. The posterior view of the atypical S situated both in right (1) and left side (1 and 2) and represented by muscular slips; C. Anterior (A) and posterior (B) views of the atypical $S\left(^{*}\right)$ situated in both sides and represented by muscular slips; PM — pectoralis major; RS — rectus sheath; $\mathrm{TT}$ - transverse thoracis muscle.

"pectoralis intermedius" or "pectoralis tertius" or "xiphihumeralis", "pectoralis quartus", "chondroepi- trochlearis" or "costoepitrochlearis" or "thoracoepicondylaris" or "chondrohumeralis" or "chondrobrachialis" or "costohumeralis", "chondrofascialis muscle", "pectoralis minimus" or "sternocostocoracoidian" or "sternochondrocoracoideus" or "chondrocoracoideus ventralis" or "sternochondrocoracoideus ventralis", "chondrocoracoideus muscle" or "muscle of Wood". We have included cadaveric, surgical and radiological studies published in English language and excluded publications where necessary data for conclusions were missing. Concerning the accessory muscles, where studies of large series of subjects were available, we have excluded cases reports. Regarding very rare accessory muscles, the cases reports were included.

\section{RESULTS}

\section{Anatomical study}

Among 48 cadavers, 2 accessory muscles of the anterior thoracic wall were found, while no accessory muscle in the axilla was encountered. The first finding was a unique $S$ found in an 18-year-old male cadaver and such a finding has not been described before. The bilateral and asymmetrical $S$ extended on the anterior and posterior surface of the sternum (Fig. 1A, B): a finding that is considered extremely rare. The PM sternocostal origin was absent. On the anterior surface of the sternum, the muscular slips of the bilateral $\mathrm{S}$ extended from the $1^{\text {st }}$ to the $4^{\text {th }}$ costal cartilage on the left side, while the right muscular slip was running from the $2^{\text {nd }}$ to the $4^{\text {th }}$ costal cartilage. The length of the right muscular slip was $6.5 \mathrm{~cm}$. The left muscular slip had two fibrous attachments and a length of $10 \mathrm{~cm}$ and $3 \mathrm{~cm}$, respectively (Figs. 1A, 1C-a). On the posterior surface of the sternum, on the left side there was an atypical fibrous bundle of $12 \mathrm{~cm}$ length extending from the $2^{\text {nd }}$ to the $6^{\text {th }}$ costal cartilage and was attached to the posterior surface of the sternum. On the right side, a $16 \mathrm{~cm}$ bundle was attached to the sternothyroid muscle. This bundle was fibrous until the $2^{\text {nd }}$ costal cartilage and continued as muscular; at the $4^{\text {th }}$ costal cartilage it bifurcated into two fibrous bundles which were attached to the $5^{\text {th }}$ costal cartilage and through the posterior layer of rectus sheath it attached to the transverse thoracis muscle (Fig. 1B, 1C-b).

The second finding was a left-sided CC (of Wood), detected in a 78-year-old male cadaver. CC was an extension of the PM abdominal portion (Fig. 2). On the ipsilateral side, the CC coexisted with a CB of one head, arising from the medial border of the tendon of the $B B$ short head. The left accessory CC, emerging with three 


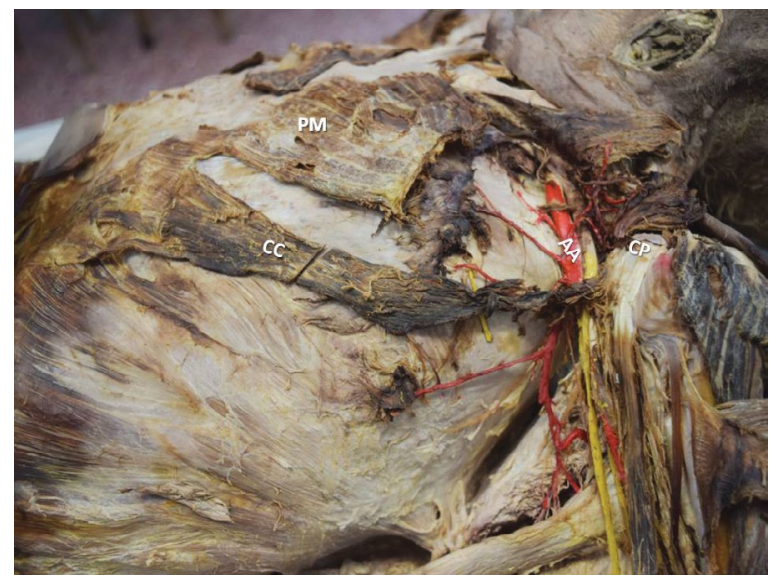

Figure 2. Left axillopectoral area. The abdominal portion of pectoralis major (PM) is an accessory pectoral muscle named the chondrocoracoideus muscle (CC) emerging by three slips from the $6^{\text {th }}$ to $8^{\text {th }}$ ribs and the external oblique muscle aponeurosis, and inserted onto the coracoid process (CP) after its fusion with the tendon of the short head of the biceps brachii; AA - axillary artery.

slips from the $6^{\text {th }}-8^{\text {th }}$ ribs and the EOM aponeurosis. At the level of the $5^{\text {th }}$ and $6^{\text {th }}$ ribs, the accessory muscle was fused to the PM sternocostal portion and inserted into the $\mathrm{CP}$ after its fusion with the tendon of the $\mathrm{BB}$ short head. The CC was innervated by the medial pectoral nerve, and supplied by the lateral thoracic artery [90]. The incidence of both muscles in our sample was $2.08 \%$ for each one of them. No LAA, Pq, Pm and CE were found in any of the cadavers that we dissected.

\section{Langer's axillary arch incidence among studies}

Based on the literature review, 13 cadaveric studies (893 cadavers) were included for the calculation of the LAA incidence. Ninety-two (10.3\%) LAAs were detected in 893 cadavers. Among them, in 31 cadavers, the LAA appeared unilaterally $(72.09 \%)$ and in 12 cadavers bilaterally ( $27.91 \%)$, in 11 out of 20 (55\%) of the cases, it was located on the right hemithorax and 12 out of $18(66.67 \%)$ cadavers with a LAA were male. Three imaging studies (2 ultrasound [U/S] and 1 computed tomography [CT] with 2511 patients) were found to highlight the LAA appearance. The LAA was detected in 190 out of 2511 (7.57\%) cases in total, in 59 out of 550 cases in CT (10.73\%) and in 121 out of 1961 (6.17\%) cases in U/S. Gender details were given for 131 patients, out of whom 107 (81.68\%) were men. Eight studies (1859 patients) were based on surgical findings regarding LAA. Thirty-six LAAs were found in 1859 (1.94\%) patients. Gender details were only available for 13 patients ( 7 male and 6 female, $53.85 \%$ and $46.15 \%$, respectively).

\section{Sternalis muscle incidence among studies}

Eleven cadaveric studies ( 2880 cadavers) were included for the calculation of the $\mathrm{S}$ incidence. Two hundred and twenty-one $S(7.67 \%)$ were detected in $149(67.42 \%)$ male and 72 (32.58\%) female cadavers. Among them, in 40 (27.21\%) cadavers, the S appeared bilaterally and in 107 (72.79\%) cadavers unilaterally. In order to find the incidence of bilateral appearance of this atypical muscle, only studies with information of laterality were included. Thus, S was right-sided in 72 (67.29\%) cases and left-sided in 35 (32.71\%) cases. Five imaging (3 CT and 2 mammography [M]) studies with 93265 patients were also included, in which $547 \mathrm{~S}(0.59 \%)$ in 272 males (49.73\%) and 275 (50.27\%) females were encountered (377 unilateral, $69.43 \%$ and 166 bilateral cases, $30.57 \%$ ). In 3 CT studies (8335 patients), S was detected in 533 cases (incidence of $6.39 \%$ ), in 367 $(68.86 \%)$ cases unilaterally and in $166(31.14 \%)$ cases bilaterally. Among cases with unilateral occurrence, $S$ was detected in $228(62.13 \%)$ cases on the right side, in $137(37.33 \%)$ cases on the left side and in $2(0.54 \%)$ cases $\mathrm{S}$ was crossed. Two hundred and seventy-two (51.03\%) males and 261 (48.97\%) females had the S. In $2 \mathrm{M}$ (84930 patients) the very low number of 14 subjects $(0.02 \%)$ was recorded. In 2 studies based on surgery (2302 patients), $11 \mathrm{~S}$ were found $(0.48 \%)$.

It is evident that the sensitivity of studies with $M$ and surgery is very low, thus only the cadaveric and CT studies were included in the calculation of the incidence of the atypical muscles of the anterior thoracic wall and axilla. Thus, 11215 subjects were encountered in 14 studies and $754 \mathrm{~S}$ were found $(6.72 \%)$ in 420 (54.76\%) males and 347 (45.24\%) females. The $S$ occurred unilaterally in 474 (69.71\%) cases (300 cases on the right, 172 cases on the left and 2 cases were crossed) and bilaterally in 206 (30.29\%) cases (Tables 1-3).

\section{Pectoralis quartus muscle incidence among studies}

A single cadaveric study (119 cadavers) encountering $3(2.52 \%)$ Pq was found. All 3 muscles were detected unilaterally (2 right and 1 left sided) (Table 1).

\section{Pectoralis minimus muscle incidence among studies}

A single cadaveric study (65 cadavers) encountering 1 (1.54\%) Pm was found (Table 1).

\section{Chondroepitrochlearis muscle incidence among studies}

Two cadaveric studies (319 cadavers) encountering $2(0.63 \%)$ CE were found (Table 1$)$. 
Table 1. The incidence of accessory muscles among cadaveric studies (C)

\begin{tabular}{|c|c|c|c|c|c|c|c|c|c|c|c|}
\hline Variants & Authors & Year & Study & Total & $\mathbf{N}(\%)$ & B & $\mathbf{U}$ & Right & Left & Male & Female \\
\hline \multirow[t]{14}{*}{ LAA } & Turki and Adds [82] & 2017 & $C$ & 280 & $3(1.07 \%)$ & & & & & & \\
\hline & Natsis et al. [57] & 2010 & C & 107 & $5(4.67 \%)$ & & 5 & 2 & 3 & & \\
\hline & Bertone et al. [10] & 2008 & C & 39 & $9(23.08 \%)$ & 1 & 8 & & & & \\
\hline & Georgiev et al. [31] & 2007 & C & 56 & $2(3.57 \%)$ & & 2 & 1 & 1 & 1 & 1 \\
\hline & Kalaycioglu et al. [40] & 1998 & C & 60 & $1(1.67 \%)$ & & 1 & 1 & & & \\
\hline & Kasai et al. [43] & 1977 & C & 88 & $46(52.27 \%)$ & & & & & & \\
\hline & Miguel et al. [55] & 2001 & C & 50 & $3(6 \%)$ & & 3 & 2 & 1 & 1 & 2 \\
\hline & Perrin [60] & 1871 & C & 58 & $10(17.24 \%)$ & 8 & 2 & & 2 & 8 & 2 \\
\hline & Rizk et al. [65] & 2008 & C & 35 & $3(8.57 \%)$ & & 3 & 1 & 2 & 2 & 1 \\
\hline & Takafuji et al. [76] & 1991 & C & 47 & $5(10.64 \%)$ & 2 & 3 & & & & \\
\hline & Merida-Velasco et al. [54] & 2003 & C & 32 & $3(9.38 \%)$ & 1 & 2 & 2 & & & \\
\hline & Bharambe et al. [12] & 2013 & C & 15 & $1(6.67 \%)$ & & 1 & 1 & & & \\
\hline & Turgut et al. [81] & 2005 & C & 26 & $1(3.85 \%)$ & & 1 & 1 & & & \\
\hline & Total LAAs & & C & 893 & $92(10.3 \%)$ & 12 & 31 & 11 & 9 & 12 & 6 \\
\hline \multirow[t]{12}{*}{ Sternalis muscle (S) } & Adachi [1] & 1909 & C & 183 & $27(14.75 \%)$ & 11 & 16 & 10 & 6 & 16 & 11 \\
\hline & Locchi [52] & 1930 & C & 303 & 30 (9.90\%) & 5 & 25 & 17 & 8 & 23 & 7 \\
\hline & Barlow [6] & 1935 & C & 535 & $33(6.17 \%)$ & 5 & 28 & 17 & 11 & 23 & 10 \\
\hline & Mori [56] & 1964 & C & 375 & $39(10.40 \%)$ & 14 & 25 & 17 & 8 & 36 & 3 \\
\hline & Bergman et al. [7] & 1988 & C & 1000 & 74 (7.40\%) & & & & & 36 & 38 \\
\hline & Jeng and Su [39] & 1998 & C & 207 & $2(0.97 \%)$ & 2 & & & & 2 & 0 \\
\hline & Londhe et al. [53] & 2010 & C & 10 & $1(10 \%)$ & & 1 & 1 & & 0 & 1 \\
\hline & Raikos et al. [63] & 2011 & C & 45 & $1(2.22 \%)$ & & 1 & & 1 & 1 & 0 \\
\hline & Chaijaroonkhanarak et al. [17] & 2013 & C & 117 & $10(8.55 \%)$ & 1 & 9 & 9 & & 9 & 1 \\
\hline & Katara et al. [44] & 2013 & C & 30 & $1(3.33 \%)$ & & 1 & 1 & & 1 & 0 \\
\hline & Saeed et al. [67] & 2002 & C & 75 & $3(4 \%)$ & 2 & 1 & & 1 & 2 & 1 \\
\hline & Total S & & C & 2880 & $221(7.67 \%)$ & 40 & 107 & 72 & 35 & 149 & 72 \\
\hline \multirow[t]{3}{*}{ CE } & Flaherty et al. [29] & 1999 & C & 200 & $1(0.50 \%)$ & 1 & & & & & 1 \\
\hline & Natsis et al. [58] & 2012 & C & 119 & $1(0.84 \%)$ & & 1 & & 1 & 1 & \\
\hline & Total & & C & 319 & $2(0.63 \%)$ & 1 & 1 & & & & \\
\hline PO & Natsis et al. [57] & 2010 & C & 119 & $3(2.52 \%)$ & & 3 & 2 & 1 & & \\
\hline Muscles variants — PM & Turgut et al. [80] & 2000 & C & 65 & $1(1.54 \%)$ & 1 & & & & & \\
\hline
\end{tabular}

LAA — Langer's axillary arch; CE — chondroepitrochlearis; PQ — pectoralis quartus; $\mathrm{PM}$ - pectoralis minimus; $\mathrm{B}$ - bilaterally; $\mathrm{U}$ - unilaterally

\section{DISCUSSION}

The pectoral muscle mass develops from the hypaxial part of the associated somites and gives rise to PM and pm. An abnormal development of the pectoral muscle mass may result in partial or complete absence of a muscle or give rise to a variant or accessory one [20]. Pectoral muscles genesis from the panniculus carnosus is a plausible theory. Muscles' remnants were identified in between the superficial fascia and subcutaneous tissue. Pq may be a remnant of the ventral part of the subcutaneous trunci muscle in lower mammals, differing from the LAA which was derived from the dorsocranial part of the muscle [71]. CE is a remnant of the most inferior insertion part of PM [29].

It is evident that cadaveric studies have the higher sensitivity in calculating the total prevalence of the atypical muscles in the general population, while the sensitivity of studies with $M$ and surgery is very low. Thus only the cadaveric and CT studies were included in the calculation of the incidence of the atypical muscles of the anterior thoracic wall and axilla. 
Table 2. The incidence of accessory muscles among imaging studies

\begin{tabular}{|c|c|c|c|c|c|c|c|c|c|c|c|c|}
\hline Variants & Authors & Year & Study & Total & $\mathbf{N}(\%)$ & B & $\mathbf{U}$ & Right & Left & Crossed & Male & Female \\
\hline \multirow[t]{4}{*}{ LAA } & Clarys et al. [21] & 1996 & $\mathrm{U} / \mathrm{S}$ & 1321 & 112 (8.48\%) & & & & & & 99 & 13 \\
\hline & Ando et al. [3] & 2010 & CT & 550 & $59(10.73 \%)$ & & 59 & & & & & \\
\hline & Van Hoof et al. [85] & 2008 & $\mathrm{U} / \mathrm{S}$ & 640 & $19(2.97 \%)$ & 7 & 12 & & & & 8 & 11 \\
\hline & Total & & & 2511 & $190(7.57 \%)$ & 7 & 71 & & & & 107 & 24 \\
\hline \multirow[t]{6}{*}{ Sternalis muscle (S) } & Bradley et al. [15] & 1996 & M & 32000 & $4(0.01 \%)$ & 0 & 0 & 10 & 6 & 0 & 0 & 4 \\
\hline & Young Lee et al. [90] & 2006 & CT & 1387 & $86(6.20 \%)$ & 23 & 63 & 35 & 28 & 0 & 42 & 44 \\
\hline & Demirpolat et al. [25] & 2010 & M & 52930 & $10(0.02 \%)$ & 0 & 10 & 10 & 0 & 0 & 0 & 10 \\
\hline & Shiotani et al. [73] & 2012 & CT & 948 & $100(10.55 \%)$ & 25 & 75 & 45 & 28 & 2 & 43 & 57 \\
\hline & Ge et al. [30] & 2014 & CT & 6000 & $347(5.78 \%)$ & 118 & 229 & 148 & 81 & 0 & 187 & 160 \\
\hline & Total & & & 93265 & $547(0.59 \%)$ & 166 & 377 & 248 & 143 & 2 & 272 & 275 \\
\hline
\end{tabular}

LAA — Langer's axillary arch; U/S — ultrasound sonography; CT — computed tomography scan; $\mathrm{M}$ — mammography; B — bilaterally; $\mathrm{U}$ — unilaterally

Table 3. The incidence of accessory muscles among surgical studies (S)

\begin{tabular}{|c|c|c|c|c|c|c|c|c|c|c|c|c|}
\hline Variants & Authors & Year & Study & Total & $\mathbf{N}(\%)$ & B & $\mathbf{U}$ & Right & Left & Crossed & Male & Female \\
\hline \multirow[t]{9}{*}{ LAA } & Haninec et al. [32] & 2009 & $S$ & 209 & $4(1.91 \%)$ & & & & & & 3 & 1 \\
\hline & Khan et al. [47] & 2012 & S & 73 & $4(5.48 \%)$ & & 4 & & & & & \\
\hline & Ridgway et al. [64] & 2011 & S & 319 & $3(0.94 \%)$ & & & & & & & \\
\hline & Kuhyanawala et al. [49] & 1998 & $S$ & 100 & $6(6.0 \%)$ & & & & & & & \\
\hline & Upasna Kumar et al. [84] & 2015 & $S$ & 50 & $2(4.0 \%)$ & & 2 & & & & & \\
\hline & Karanlik et al. [42] & 2013 & S & 758 & $9(1.19 \%)$ & & 9 & & & & 4 & 5 \\
\hline & Chene et al. [18] & 2007 & $S$ & 304 & $5(1.64 \%)$ & & & & & & & \\
\hline & Besana-Ciani et al. [11] & 2005 & $S$ & 46 & $3(6.52 \%)$ & & & & & & & \\
\hline & Total LAAs & & S & 1859 & $36(1.94 \%)$ & & 15 & & & & 7 & 6 \\
\hline \multirow[t]{3}{*}{ Sternalis muscle (S) } & Harish and Gopinath [33] & 2003 & $S$ & 1152 & $8(0.69 \%)$ & & & & & & & 8 \\
\hline & Khan [46] & 2008 & $S$ & 1150 & $3(0.26 \%)$ & & 2 & 2 & & & & 3 \\
\hline & Total S & & S & 2302 & $11(0.48 \%)$ & & & & & & & 11 \\
\hline
\end{tabular}

LAA — Langer's axillary arch; B — bilaterally; U - unilaterally

\section{Coexistence of the accessory thoracic wall muscles}

The accessory muscles of the anterior thoracic wall and axilla may occur isolated or in combination with other abnormal muscles. Bonastre et al. [14] reported an interesting case of Pq occurring alongside a LAA, in which $\mathrm{Pq}$ inserted into the inferomedial aspect of LAA instead of the usual bicipital groove insertion. A similar case was reported by Bergman [8], where a double $\mathrm{Pq}$ inserted into a LAA. Fabrizio and Hardy [28] noted a case of Pq occurring along another accessory thoracic muscle on the left side of a 60 -yearold male cadaver. The $\mathrm{Pq}$ arose from the $5^{\text {th }}$ costal cartilage overlying pm origin and coursed superiorly to insert into $C B$ fascia, while the accessory muscle arose from the EOM aponeurosis and inserted into the CB fascia, deep to $P q$ insertion. CE has a high predilection to occur simultaneously with a LAA $[8,19,50,51,75]$, although it has been reported to exist isolated [29, 36, 68, 69, 87]. Chiba et al. [19] and Lama et al. [50] reported a rare case of CE occurring along with the LAA. In Chiba et al. [19] case, the CE arose via two slips from the lower costal cartilages. Bryce [16] reported a case with multiple supernumerary muscles (the $C E, S$, and sternoclavicularis) on the right hemithorax of a female cadaver and a deficit in the PM sternal portion.

\section{Clinical significance}

The clinical significance of the accessory muscles of the anterior thoracic wall remains controversial. 
The controversy may be attributed to the rare occurrence of these anatomical variants, as well as to lack of clinician awareness often leading to failure reporting or identification. It has been well observed that intraoperative recognition of muscular variants in a given anatomical region can reflect awareness of the variant itself, but not necessarily its respective surgical significance [57]. Accessory muscles of the anterior thoracic wall are not routinely mentioned in descriptive or surgical anatomy textbooks. In this context, even experienced breast or thoracic surgeons may fail to recognise the variants in the operative field [66]. We contend that the purpose of a surgical dissection may be very different as compared to the fine descriptive nature of cadaveric dissections carried out for teaching or research [57].

Failure to recognise the accessory muscles preoperatively or intraoperatively is not always complication-free. Most often though, division of the accessory muscles is carried out without functional deficit for the patient and in certain cases, may be advisable in order to manage symptoms presumably related to the variants presence $[51,57]$.

Evidence supporting the clinical significance of muscle variants in the anterior thoracic wall is quite sparse and does not allow drawing safe conclusions. LAA and $\mathrm{S}$ have been more widely described in literature than other variants. There is no clarity as to the clinical importance of the accessory muscles that appear less often than the aforementioned variants, given the paucity of data on their intraoperative recognition [57]. Nevertheless, most publications pertaining to the commonest accessory muscles are cadaveric studies, where clinical data regarding symptoms or surgical complications due to the presence of those muscles are unavailable. There are few studies to have included imaging or surgical data; however, these were mainly designed to investigate the prevalence of these muscles and not potential surgical implications related to their presence. The main body of the literature related to symptomatic presence of an accessory muscle is case reports. Most references regarding the clinical significance of the accessory muscles are usually based on assumptions, after taking into consideration published data, as well as the anatomical area where an accessory muscle lies, which consequently does not provide us with high quality data.

LAA. The accessory muscles that run through the axillary basin may alter the operative field boundaries and impact on surgical procedures in the axilla, such as axillary node clearance, sentinel lymph node biopsy and LD myocutaneous flap reconstruction [57]. The clinical implications of the occurrence of accessory muscles in the axilla have mainly been studied with regards to LAA [23, 72]. During sentinel node biopsy, LAA may cause delays by transposing the lymph nodes to a higher level, as it stretches in the hyper-abducted position [45]. It can also lead to modification of the axillary node clearance [57], as it can be mistaken for the lateral margin of $L D$, divert the dissection into a plane above the axillary vein and thus increase the risk of neurovascular injury [57].

It may also conceal the lateral group of level I axillary lymph nodes, whilst crossing over the axillary vein [57]. Consequently, the surgeon may overlook nodes sitting at the lateral edge of the axillary basin, leading to suboptimal nodal dissection, increased risk of axillary recurrence in breast cancer patients, as well as inaccurate staging due to less nodal retrieval [61]. LAA presence has also been correlated with increased risk of lymphoedema following LD reconstruction [45]. In view of the above complications, identification of the LAA during regional dissections may be crucial $[23,72]$ and division at the level of axillary vein is deemed necessary [2]. Division of the arch leads to clear identification of the anatomic landmarks of the axillary basin and prevents axillary vein compression and associated lymphoedema $[45,61]$. Moreover, the LAA presence can obscure clinical examination when palpable, as it can misguide towards a diagnosis of an axillary mass or lymphadenopathy $[41,45]$. Finally, arm movement in the presence of a LAA may cause entrapment of the neurovascular bundle, leading to circulatory deficiency, chronic pain and paraesthesia [38, 42].

Sternalis muscle. $S$ presence on the abdominal wall imaging can reportedly complicate diagnosis of regional abnormalities, as it is depicted as focal density in the medial breast on mammograms, often mimicking a neoplasm. Understanding of this anatomical variant is clinically meaningful, as it may avoid unnecessary invasive procedures that can lead to complications, increase cost and impact on patient anxiety $[15,25,67]$. Moreover, $\mathrm{S}$ has been reported to impact on breast and thoracic surgery as it can cause delays if unrecognised [70]. When detected pre-surgery, it can be used as a muscle flap in sub-pectoral breast reconstruction and potentially improve aesthetic results or reduce the cost by avoiding the 
use of acellular dermal matrix, in order to fully cover the prosthesis. It can also be used in breast augmentation by providing extra cover for the prosthesis and improve cosmesis [35]. Enlarged S may impact on sub-pectoral breast reconstruction, as it is often associated with a defect in the medial aspect of the ipsilateral PM, which exposes the costal cartilages medially [22, 34, 59, 83]. In such cases, provided the presence of $S$ is known preoperatively, a pre-pectoral approach for the breast reconstruction might be more appropriate. Alternatively, lifting both PM and S, in order to provide implant cover and to be able to place the implant medially might be necessary, in cases where a subpectoral approach is decided. If $\mathrm{S}$ presence is not known preoperatively, it can lead to unwanted alterations of the surgical plan.

$\mathrm{Pm}$. As thoracoacromial vessels run anteriorly and posteriorly to $\mathrm{Pm}$, there is risk of compression or impingement during shoulder hyperabduction, leading to pain associated with movement and possible impact on the muscular dynamics of the joint $[62,80]$.

$\mathrm{Pq}$ and Pi. Pq presence may complicate the axillary node clearance, by limiting the surgical field $[61,78]$. Failure to recognise the muscle may transpose the dissection to a lower level [57]. Once Pq is identified intraoperatively, it can be retracted along with the PM lateral margin. Pq should be divided, as it bears similar appearance to the CE [57]. Pm is believed to portend similar clinical significance.

CE. The need for surgical dissection and release of the CE has been reported $[26,87]$ and associated to complications during axillary node clearance [57, 58], as well as nerve impingement [75], shoulder contractures [51] and functional impairment by limiting abduction of the shoulder joint. Natsis et al. [57] recommended its division in order to prevent unwanted modifications in the course of the procedure during axillary node clearance.

\section{CONCLUSIONS}

Despite the fact that accessory muscles of the anterior thoracic wall and axilla are considered to be rare, it is evident that the incidence of at least some of them is high enough to encounter them in clinical practice. It is therefore needless to say that it is crucial not only for anatomists but also for clinicians to be aware of these anatomical variants as they can affect their clinical practice.

\section{Acknowledgements}

The authors thank the physician Nikitas-Apollon Panagiotopoulos for his valuable assistance with the schematic drawings of the paper.

\section{REFERENCES}

1. Adachi B. Beitrage zur anatomie der Japaner. Z Morphol Anthropol. 1909; 12: 261-312.

2. Al Maksoud AM, Barsoum AK, Moneer MM. Langer's arch: a rare anomaly affects axillary lymphadenectomy. J Surg Case Rep. 2015; 2015(12), doi: 10.1093/jscr/rjv159, indexed in Pubmed: 26712801.

3. Ando J, Kitamura T, Kuroki Y, et al. Preoperative diagnosis of the axillary arch with multidetector row computed tomography and the axillary arch in association with anatomical problems of sentinel lymph node biopsy. Breast Cancer. 2010; 17(1): 3-8, doi: 10.1007/s12282-009-0138-4, indexed in Pubmed: 19585215.

4. Arican RY, Coskun N, Sarikcioglu L, et al. Co-existence of the pectoralis quartus and pectoralis intermedius muscles. Morphologie. 2006; 90(290): 157-159, indexed in Pubmed: 17278455.

5. Barcia JM, Genovés JM. Chondrofascialis versus pectoralis quartus. Clin Anat. 2009; 22(8): 871-872, doi: 10.1002/ ca.20798, indexed in Pubmed: 19418449.

6. Barlow R. The sternalis muscle in American whites and negroes. Anat Rec. 1935; 61(4): 413-426, doi: 10.1002/ ar.1090610405.

7. Bergman RA, Thompson SA, Afifi AK. Compen- dium of human anatomic variations. Urban and Schwarzenberg, Baltimore, Munich 1988.

8. Bergman RA. Doubled pectoralis quartus, axillary arch, chondroepitrochlearis, and the twist of the tendon of pectoralis major. Anat Anz. 1991; 173(1): 23-26, indexed in Pubmed: 1952092.

9. Bergman RA. Anatomy atlases: illustrated encyclopedia of human anatomic variation. 2014. http://www.anatomyatlases.org/ (accessed 16 October 2015).

10. Bertone VH, Ottone NE, Lo Tartaro $M$, et al. The morphology and clinical importance of the axillary arch. Folia Morphol. 2008; 67(4): 261-266, indexed in Pubmed: 19085866.

11. Besana-Ciani I, Greenall MJ. Langer's axillary arch: anatomy, embryological features and surgical implications. Surgeon. 2005; 3(5): 325-327, doi: 10.1016/s1479 666x(05)80111, indexed in Pubmed: 16245651.

12. Bharambe V, Arole V. The axillary arch muscle (Langer's muscle): Clinical importance. Med J DY Patil Univ. 2013; 6(3): 27-30, doi: 10.4103/0975-2870.114680.

13. Birmingham A. Homology and innervation of the achselbogen and pectoralis quartus, and the nature of the lateral cutaneous nerve of the thorax. J Anat Physiol. 1889; 23(Pt 2): 206-223, indexed in Pubmed: 17231782.

14. Bonastre V, Rodríguez-Niedenführ M, Choi D, et al. Coexistence of a pectoralis quartus muscle and an unusual axillary arch: case report and review. Clin Anat. 2002; 15(5): 366-370, doi: 10.1002/ca.10053, indexed in Pubmed: 12203382. 
15. Bradley FM, Hoover HC, Hulka CA, et al. The sternalis muscle: an unusual normal finding seen on mammography. AJR Am J Roentgenol. 1996; 166(1): 33-36, doi: 10.2214/ ajr.166.1.8571900, indexed in Pubmed: 8571900.

16. Bryce TH. Note on a Group of Varieties of the Pectoral Sheet of Muscle. J Anat Physiol. 1899; 34(Pt 1): 75-78, indexed in Pubmed: 17232412.

17. Chaijaroonkhanarak W, Amarttayakong P, Pannangrong W, et al. Incidence of the sternalis muscle in Northeastern Thais Srinagarind. Med J. 2013; 28: 62-65.

18. Chêne G, Bouëdec GLe, Dauplat J. L'arche et la sentinelle: techniques chirurgicales de la lymphadénectomie axillaire sentinelle en présence du muscle pectoro-axillaire. Gynecol Obstet Fertil. 2007; 35(1): 25-29, doi: 10.1016/j. gyobfe.2006.10.031.

19. Chiba S, Suzuki T, Kasai T. A rare anomaly of the pectoralis major--the chondroepitrochlearis. Okajimas Folia Anat Jpn. 1983; 60(2-3): 175-185, indexed in Pubmed: 6646611.

20. Clark E. Congenital Variation of the Pectoral Muscles, with Report of a Case. J Anat Physiol. 1915; 49(Pt 2): 155-164, indexed in Pubmed: 17233021.

21. Clarys JP, Barbaix E, Van Rompaey H, et al. The muscular arch of the axilla revisited: its possible role in the thoracic outlet and shoulder instability syndromes. Man Ther. 1996; 1(3): 133-139, doi: 10.1054/math.1996.0261, indexed in Pubmed: 11440500.

22. Cunningham DJ. The musculus sternalis. J Anat Physiol. 1884; 18(Pt 2): 208-210, indexed in Pubmed: 17231521.

23. Daniels IR, della Rovere GQ. The axillary arch of Langer - the most common muscular variation in the axilla. Breast Cancer Res Treat. 2000; 59(1): 77-80, indexed in Pubmed: 10752682.

24. Del Sol M, Vásquez B. Anatomical and clinical considerations of the pectoralis tertius muscle in man. Int J Morphol. 2009; 27(3), doi: 10.4067/s0717-95022009000300014.

25. Demirpolat G, Oktay A, Bilgen I, et al. Mammographic features of the sternalis muscle. Diagn Interv Radiol. 2010; 16(4): 276-278, doi: 10.4261/1305-3825.DIR.2733-09.2, indexed in Pubmed: 20700868.

26. Di Gennaro GL, Soncini G, Andrisano A, et al. The chondroepitrochlearis muscle: case report. Chir Organi Mov. 1998; 83(4): 419-423, indexed in Pubmed: 10369023.

27. Ebenezer DA, Rathinam BAD. Rare multiple variations in brachial plexus and related structures in the left upper limb of a Dravidian male cadaver. Anat Cell Biol. 2013; 46(2): 163-166, doi: 10.5115/acb.2013.46.2.163, indexed in Pubmed: 23869264.

28. Fabrizio PA, Hardy MA. An accessory muscle of the thoracic wall. Int J Anat Var. 2009; 2: 93-95.

29. Flaherty G, O'Neill MN, Folan-Curran J. Case report: bilateral occurrence of a chondroepitrochlearis muscle. J Anat. 1999; 194 ( Pt 2): 313-315, doi: 10.1046/j.14697580.1999.19420313.x, indexed in Pubmed: 10337965.

30. Ge Z, Tong Y, Zhu S, et al. Prevalence and variance of the sternalis muscle: a study in the Chinese population using multi-detector CT. Surg Radiol Anat. 2014; 36(3): 219-224, doi: 10.1007/s00276-013-1175-4, indexed in Pubmed: 23912561.
31. Georgiev GP, Jelev L, Surchev L. Axillary arch in Bulgarian population: clinical significance of the arches. Clin Anat. 2007; 20(3): 286-291, doi: 10.1002/ca.20369, indexed in Pubmed: 16838267.

32. Haninec $P$, Tomás $R$, Kaiser $R$, et al. Development and clinical significance of the musculus dorsoepitrochlearis in men. Clin Anat. 2009; 22(4): 481-488, doi: 10.1002/ ca.20799, indexed in Pubmed: 19373904.

33. Harish K, Gopinath KS. Sternalis muscle: importance in surgery of the breast. Surg Radiol Anat. 2003; 25(3-4): 311-314, doi: 10.1007/s00276-003-0119-9, indexed in Pubmed: 12898192.

34. Huntington GS. The derivation and significance of certain supernumerary muscles of the pectoral region. J Anat Physiol. 1904; 39(Pt 1): 1-54, indexed in Pubmed: 17232622.

35. Ishii N, Shimizu Y, Ando J, et al. Complete coverage of a tissue expander by a musculofascial pocket including the sternalis muscle during breast reconstruction. Arch Plast Surg. 2018; 45(1): 89-90, doi: 10.5999/aps.2017.00017, indexed in Pubmed: 29076323.

36. Jaijesh P. Unilateral appearance of a chondro-epitrochlearis muscle-a case report. Indian J Plast Surg. 2005; 38(2): 164, doi: 10.4103/0970-0358.19791.

37. Jelev L, Georgiev G, Surchev L. The sternalis muscle in the Bulgarian population: classification of sternales. J Anat. 2001; 199(Pt 3): 359-363, doi: 10.1046/j.14697580.2001.19930359.x, indexed in Pubmed: 11554516.

38. Jelev L, Georgiev GP, Surchev L. Axillary arch in human: common morphology and variety. Definition of "clinical" axillary arch and its classification. Ann Anat. 2007; 189(5): 473-481, doi: 10.1016/j.aanat.2006.11.011, indexed in Pubmed: 17910401.

39. Jeng $\mathrm{H}$, Su SJ. The sternalis muscle: an uncommon anatomical variant among Taiwanese. J Anat. 1998; 193 (Pt 2): 287-288, doi: 10.1046/j.1469-7580.1998.19320287.x, indexed in Pubmed: 9827644.

40. Kalaycioglu A, Gümüsalan Y, Ozan H. Anomalous insertional slip of latissimus dorsi muscle: arcus axillaris. Surg Radiol Anat. 1998; 20(1): 73-75, indexed in Pubmed: 9574494.

41. Kanaka S, Pulipati A, Gaikwad M. Axillary arch and its relations - a rare case report. Int J Biol Med Res. 2012; 3: 2277-2779.

42. Karanlik $H$, Fathalizadeh A, Ilhan B, et al. Axillary arch may affect axillary lymphadenectomy. Breast Care. 2013; 8(6): 424-427, doi: 10.1159/000357307, indexed in Pubmed: 24550750 .

43. Kasai T, Chiba S. [True nature of the muscular arch of the axilla and its nerve supply (author's transl)]. Kaibogaku Zasshi. 1977; 52(5): 309-336, indexed in Pubmed: 596123.

44. Katara P, Chauhan S, Arora R, et al. A unilateral rectus sternalis muscle: rare but normal anatomical variant of anterior chest wall musculature. J Clin Diagn Res. 2013; 7(12): 2665-2667, doi: 10.7860/JCDR/2013/7379.3726, indexed in Pubmed: 24551605.

45. Kataria K, Srivastava A, Mandal A. Axillary arch muscle: a case report. Eur J Anat. 2013; 17: 259-261. 
46. Khan UD. Use of the rectus sternalis in augmentation mammoplasty: case report and literature search. Aesthetic Plast Surg. 2008; 32(1): 21-24, doi: 10.1007/s00266-0079046-1, indexed in Pubmed: 17965818.

47. Khan A, Chakravorty A, Gui GPH. In vivo study of the surgical anatomy of the axilla. Br J Surg. 2012; 99(6): 871-877, doi: 10.1002/bjs.8737, indexed in Pubmed: 22505319.

48. Knott JF. Muscular anomalies. J Anat Physiol. 1880; 15(Pt 1): 139-140, indexed in Pubmed: 17231366.

49. Kutiyanawala MA, Stotter A, Windle R. Anatomical variants during axillary dissection. Br J Surg. 1998; 85(3): 393-394, doi: 10.1046/j.1365-2168.1998.00612.x, indexed in Pubmed: 9529501.

50. Lama P, Potu BK, Bhat KMR. Chondrohumeralis and axillary arch of Langer: a rare combination of variant muscles with unique insertion. Rom J Morphol Embryol. 2010; 51(2): 395-397, indexed in Pubmed: 20495763.

51. Lin C. Contracture of the chondroepitrochlearis and the axillary arch muscles. A case report. J Bone Joint Surg Am. 1988; 70(9): 1404-1406, indexed in Pubmed: 3182896.

52. Locchi R. Reserches d'anatomie ethnique sur le 'musculus sternalis' Comptes rendus de 1'Associations des Anatomistes. 1930; 25: 212

53. Londhe SR, Jadhav AS, Koti MN. Unilateral rectus stermalis muscle a case presentation. Anat Karnataka. 2010; 4: 51-53.

54. Mérida-Velasco JR, Rodríguez Vázquez JF, Mérida Velasco $\mathrm{JA}$, et al. Axillary arch: potential cause of neurovascular compression syndrome. Clin Anat. 2003; 16(6): 514-519, doi: 10.1002/ca.10143, indexed in Pubmed: 14566899.

55. Miguel M, Llusá M, Ortiz JC, et al. The axillopectoral muscle (of Langer): report of three cases. Surg Radiol Anat. 2001; 23(5): 341-343, indexed in Pubmed: 11824135.

56. Mori M. Statistics on the musculature of the Japanese. Okajimas Folia Anat Jpn. 1964; 40: 195-300, indexed in Pubmed: 14213705.

57. Natsis K, Vlasis K, Totlis T, et al. Abnormal muscles that may affect axillary lymphadenectomy: surgical anatomy. Breast Cancer Res Treat. 2010; 120(1): 77-82, doi: 10.1007/ s10549-009-0374-5, indexed in Pubmed: 19306056.

58. Natsis K, Totlis T, Sofidis G. Chondroepitrochlearis: an abnormal muscle that may affect axillary lymphadenectomy. ANZ J Surg. 2012; 82(4): 286-287, doi: 10.1111/j.14452197.2012.06015.x.

59. O'Neill MN, Folan-Curran J. Case report: bilateral sternalis muscles with a bilateral pectoralis major anomaly. J Anat. 1998; 193 ( Pt 2): 289-292, doi: 10.1046/j.14697580.1998.19320289.x, indexed in Pubmed: 9827645.

60 . Perrin JB. Notes on some variations of the pectoralis major, with its associate muscles. J Anat Physiol. 1871; 5(Pt 2): 233-244, indexed in Pubmed: 17230890.

61. Petrasek AJ, Semple JL, McCready DR. The surgical and oncologic significance of the axillary arch during axillary lymphadenectomy. Can J Surg. 1997; 40(1): 44-47, indexed in Pubmed: 9030083.

62. Rai R, Ranade A, Prabhu L, et al. Unilateral pectoralis minimus muscle: a case report. Int J Morphol. 2008; 26(1): 27-29, doi: 10.4067/s0717-95022008000100004.
63. Raikos A, Paraskevas GK, Yusuf F, et al. Sternalis muscle: a new crossed subtype, classification, and surgical applications. Ann Plast Surg. 2011; 67(6): 646-648, doi: 10.1097/ SAP.0b013e31820d688b, indexed in Pubmed: 21407048.

64. Ridgway PF, Collins AM, McCready DR. The surgical importance of an axillary arch in sentinel node biopsy. Surg Radiol Anat. 2011; 33(2): 147-149, doi: 10.1007/s00276010-0724-3, indexed in Pubmed: 20811892.

65. Rizk E, Harbaugh K. The muscular axillary arch: an anatomic study and clinical considerations. Neurosurgery. 2008; 63(4 Suppl 2): 316-319, doi: 10.1227/01. NEU.0000327033.22068.74, indexed in Pubmed: 18981837.

66. Sachatello CR. The axillopectoral muscle (Langer's axillary arch): a cause of axillary vein obstruction. Surgery. 1977; 81(5): 610-612, indexed in Pubmed: 850878.

67. Saeed M, Murshid KR, Rufai AA, et al. Sternalis. An anatomic variant of chest wall musculature. Saudi Med J. 2002; 23(10): 1214-1221; Erratum in: Saudi Med J. 2002; 23(12): 1561. Saudi Med J 2006; 27(6): 914, indexed in Pubmed: 12436146.

68. Samuel VP, Vollala VR. Unusual pectoralis major muscle: the chondroepitrochlearis. Anat Sci Int. 2008; 83(4): 277-279, doi: 10.1111/j.1447-073X.2007.00204.x, indexed in Pubmed: 19159358.

69. Sarikcioglu L, Yildirim FB, Chiba S. Unilateral occurrence of a chondroepitrochlearis muscle. Clin Anat. 2004; 17(3): 272-275, doi: 10.1002/ca.10179, indexed in Pubmed: 15042577.

70. Sasmal PK, Meher S, Mishra TS, et al. Sternalis muscle: an unexpected finding during mastectomy. Case Rep Surg. 2015; 2015: 723198, doi: 10.1155/2015/723198, indexed in Pubmed: 26609461.

71. Sawada M, Ishibashi $Y$, Suzuki $T$, et al. Case report on the pectoralis quadratus and the pectoralis intermedius muscles. Acta Anat Nippon. 1991; 66: 99-105.

72. Serpell JW, Baum M. Significance of 'Langer's axillary arch' in axillary dissection. Aust N Z J Surg. 1991; 61(4): 310-312, indexed in Pubmed: 2018442.

73. Shiotani $M$, Higuchi T, Yoshimura N, et al. The sternalis muscle: radiologic findings on MDCT. Jpn J Radiol. 2012; 30(9): 729-734, doi: 10.1007/s11604-012-0114-3, indexed in Pubmed: 22875586.

74. Snosek M, Tubbs RS, Loukas M. Sternalis muscle, what every anatomist and clinician should know. Clin Anat. 2014; 27(6): 866-890, doi: 10.1002/ca.22361, indexed in Pubmed: 24431029.

75. Spinner RJ, Carmichael SW, Spinner M. Infraclavicular ulnar nerve entrapment due to a chondroepitrochlearis muscle. J Hand Surg Br. 1991; 16(3): 315-317, indexed in Pubmed: 1960500

76. Takafuji T, Igarashi J, Kanbayashi T, et al. [The muscular arch of the axilla and its nerve supply in Japanese adults]. Kaibogaku Zasshi. 1991; 66(6): 511-523, indexed in Pubmed: 1816715.

77. Taterra D, Henry BM, Zarzecki MP, et al. Prevalence and anatomy of the axillary arch and its implications in surgical practice: A meta-analysis. Surgeon. 2019; 17(1): 
43-51, doi: 10.1016/j.surge.2018.04.003, indexed in Pubmed: 29801707.

78. Totlis $T$, losifidou R, Pavlidou F, et al. Complicated axillary lymphadenectomy due to a pectoralis quartus muscle. Chirurgia (Bucur). 2012; 107(3): 397-398, indexed in Pubmed: 22844841.

79. Tountas $C P$, Bergman RA. Anatomic variations of the upper extremity. Churchill Livingstone, New York. 1993: 79-81.

80. Turgut HB, Anil A, Peker T, et al. Insertion abnormality of bilateral pectoralis minimus. Surg Radiol Anat. 2000; 22(1): 55-57, indexed in Pubmed: 10863749.

81. Turgut HB, Peker T, Gülekon N, et al. Axillopectoral muscle (Langer's muscle). Clin Anat. 2005; 18(3): 220-223, doi: 10.1002/ca.20077, indexed in Pubmed: 15768417.

82. Turki MA, Adds PJ. Langer's axillary arch: a rare variant, and prevalence among Caucasians. Folia Morphol. 2017; 76(3): 536-539, doi: 10.5603/FM.a2017.0022, indexed in Pubmed: 28281725.

83. Turner W. On the Musculus Sternalis. J Anat Physiol. 1867; 1(2): 246-253, indexed in Pubmed: 17230716.

84. Upasna Kumar A, Singh B, Kaushal S. Muscular variations during axillary dissection: a clinical study in fifty patients.
Niger J Surg. 2015; 21(1): 60-62, doi: 10.4103/11176806.153196, indexed in Pubmed: 25838770.

85. Van Hoof T, Vangestel C, Forward M, et al. The impact of muscular variation on the neurodynamic test for the median nerve in a healthy population with langer's axillary arch. J Manipulative Physiol Ther. 2008; 31(6): 474-483, doi: 10.1016/j.jmpt.2008.06.007.

86. Venieratos D, Samolis A, Piagkou M, et al. The chondrocoracoideus muscle: $A$ rare anatomical variant of the pectoral area. Acta Med Acad. 2017; 46(2): 155-161, doi: 10.5644/ ama2006-124.200, indexed in Pubmed: 29338279.

87. Voto SJ, Weiner DS. The chondroepitrochlearis muscle. J Pediatr Orthop. 1987; 7(2): 213-214, indexed in Pubmed: 3558807.

88. Wallace D. Nerve supply of musculus sternalis. J Anat Physiol. 1886; 21 (Pt 1): 153-154, indexed in Pubmed: 17231660.

89. Wood J. Variations in human myology observed during the Winter Session of 1865-6 at King's College, London. Proc Royal Soc. 1866; 15: 229-244.

90. Young Lee B, Young Byun J, Hee Kim H, et al. The sternalis muscles: incidence and imaging findings on MDCT. J Thorac Imaging. 2006; 21(3): 179-183, doi: 10.1097/01. rti.0000208287.04490.db, indexed in Pubmed: 16915061. 